\title{
Electrical and Electronic Waste in Northwest Mexico
}

\author{
Sara Ojeda-Benitez ${ }^{1}$, Samantha E. Cruz-Sotelo ${ }^{2}$, Luis Velázquez ${ }^{3}$, Néstor Santillán-Soto ${ }^{1}$, \\ Margarito Quintero Nuñez ${ }^{1}$, O. Rafael García Cueto ${ }^{1}$, Will Markus ${ }^{4}$
}

\begin{abstract}
${ }^{1}$ Engineering Institute, Autonomous University of Baja California, Mexicali, Mexico; ${ }^{2}$ Faculty of Engineering, Autonomous University of Baja California, Mexicali, Mexico; ${ }^{3}$ University of Sonora, Hermosillo, Mexico; ${ }^{4}$ University of Applied Sciences Zittau/Gorlitz, Zittau, Germany.

Email: sara.ojeda.benitez@uabc.edu.mx
\end{abstract}

Received March 20 ${ }^{\text {th }}, 2013$; revised April 22 ${ }^{\text {nd }}, 2013$; accepted May $6^{\text {th }}, 2013$

Copyright (C) 2013 Sara Ojeda-Benitez et al. This is an open access article distributed under the Creative Commons Attribution License, which permits unrestricted use, distribution, and reproduction in any medium, provided the original work is properly cited.

\begin{abstract}
The waste derived from Electrical and Electronic Equipment (WEEE) is of interest now worldwide, in some countries due to the rapid technological development and in others due to technological dependence through the acquisition of second hand equipment. Therefore it is necessary to implement strategies for the sustainable management of electrical and electronic equipment at the end of its useful life. This paper presents the results of an investigation that was conducted in a city located in the Northwest of Mexico, which seeks to understand the management practices of household WEEE generators. A survey was applied to a representative sample of the population with a confidence level of $90 \%$. Six home appliances were quantified and it was found that approximately $21 \%$ of them are disposed directly as part of the household flow of Municipal Solid Waste (MSW), while 79\% are storage for a latter sale, repair or reuse. The results obtained support the need to develop evaluations and to implement possible scenarios for the sustainable management of Electrical and Electronic Waste.
\end{abstract}

Keywords: Electrical and Electronic Waste; Electronic Manufacturing Sector; Management Practices

\section{Introduction}

Waste Electrical and Electronic Equipment (WEEE) are any electrical or electronic equipment that no longer fulfill the purpose for which they were manufactured. This includes white goods (e.g., refrigerator, washing machine, microwave ovens), gray line (e.g., computers and mobile phones) and brown goods (e.g., television, radio, computers), according to the European Union's (EU's) WEEE classifications [1].

Today's generation of WEEE is growing at an alarming rate mainly in countries belonging to the Organisation for Economic Co-operation and Development (OECD) where electronic markets are saturated with new technologies [2]. Globally, it is estimated that between 20 and 50 million tons of WEEE are generated each year, and this figure is increasing at a rate of $3 \%-5 \%$ per year [3]. WEEE has a high potential for environmental contamination and damage to human health. The problem is even greater due to the lack of control in their management and disposal because a large amount of Electrical and Electronic Equipment (EEE) at the end of their life-span are mixed with Municipal Solid Waste (MSW) at disposal sites.

In 2016, the global electronic components market is forecast to have a value of $\$ 229.7$ billion, an increase of $52.1 \%$ since 2011. The compound annual growth rate of the market in the period 2011-2016 is predicted to be 8.7\% [4] (Figure 1).

In 2010, the global electronic manufacturing sector reported a 176.77 billion USD market value and is expected to grow at an average $8.7 \%$ annual rate over the next five years [5]. Products considered part of the sector

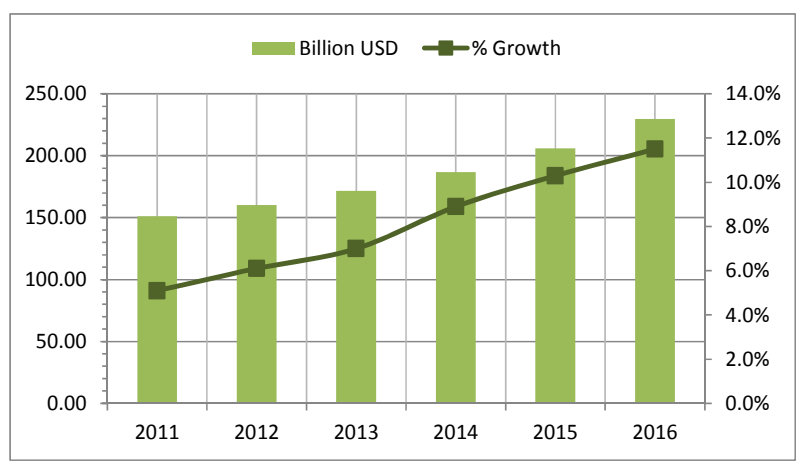

Source: Industry Profile: Global Electronic Components.

Figure 1. Global electronic components market value forecast: Billion USD, 2011-2016. 
are flat-screen television sets, cellular phones, computers, data processing machines, control units or adaptors, telephone components, semi-conductors, transmission and receptor equipment, automatic machines for data processing, microwave receivers, or signals via satellite, modular circuits and video game consoles. The number of electrical and electronic devices (computers, mobile phones, electronic games, etc.) is continuously increasing at the global scale. Their lifespan is usually short while turnover is driven by innovation. The high consumption of these products leads to growing amounts of e-wastes or WEEE the boundary between them is not clear since many types of electric equipment's include microprocessors [6].

WEEE disposed of in MSW are a complex mixture containing a variety of hazardous substances, which cause a considerable social problem and threat to the environment. These factors, coupled with current practices such as incineration, abandonment or improperly prepared disposal sites and lack of treatment, create even more problems.

WEEE are very different compared to MSW. Policies for conventional waste management are not the most appropriate to implement in the case of WEEE due to the specific characteristics of both. Although both streams contain elements that can be recovered as raw materials, they also contain highly toxic substances [2,7]. More than $60 \%$ of WEEE are valuable, while $2.70 \%$ of WEEE consist of contaminants [8]. However, the potential toxicity of these components necessitates actions and polices to be implemented for the valorization, recycling, treatment and disposal of wastes in appropriate manners.

Reference [9] seeking to characterize hazardous household waste (HHW), proposed a classification of household hazardous components or groups that encompasses WEEE because they contain dangerous substances. One must consider that, although WEEE represent a small fraction of total household waste and an even smaller amount of total MSW, the range and types of hazardous substances these WEEE contain have great potential for environmental damage and health impacts.

\section{Electronics Manufacturing in Mexico}

Electronics manufacturing (EMS) in Mexico in the Northwestern part of the country is dominated by the production of components for the aerospace, automotive and telecommunications industries, while in the Northeast EMS companies in Mexico manufacture components used in computers, home appliances, consumer goods, telecommunications and automobiles.

In Mexico, WEEE are of particular interest because they are included in the General Law for Waste Management (LGPGIR) as a waste requiring special handling.
Several factors could contribute to their generation such as a lack of resources and infrastructure, awareness of the population, absence or lack of clear legislative basis, industrial growth and the impacts of new technologies. However, particularly alarming is that, as a waste stream of fastest growing, in Mexico have not developed strategies for handling obsolete electronic products. In this country, it is estimated that, in one generation, at least 411 tons per day of WEEE will be generated. Moreover, there is no specific information on WEEE handling and disposal and that its management is performed along with MSW [10].

In Mexico, as in other developing countries, the lack of information concerning the management, risks and damage caused by mismanagement of waste has led to inappropriate practices as a recovery measure or a valuation of certain components, but the power of contamination and toxicity due to informal recycling has caused serious environmental and health concerns [11].

Mexico has a solid installed capacity for manufacture of electronic products, which was valued at 53,988 million USD in 2010. According to Global Insight's estimates, the electronics production in Mexico will increase by an annual average rate of $6.1 \%$ over the next four years.

Mexico is one of the most open economies in the world, as its international trade is equal to $58 \%$ of the GDP and represents more than $40 \%$ of the total trade in Latin America. Mexico has a solid has 728 economic units specializing in the electronic industry and located mainly in Baja California, Tamaulipas, Chihuahua. This sector employed a total of 312,913 people in 2009 [12].

Mexico is the most competitive country in the world in terms of manufacturing costs which are approximately 25\% lower than in the United States. According to the World Bank, Mexico is the best country in Latin America for doing business, and also is ranked 35th in the world. In 2011, the sector's exports totaled 62,985 million USD, representing a 10.9 growth rate over the previous year. The United States was the main destination for Mexican exports with a marker share of $85.1 \%$, followed by Canada, Colombia and Venezuela. The major electronic products exported by Mexico were flat-screen television sets, computer and others (Table 1) [13]. In addition, Mexico is well positioned as an assembler and exporter of electronic products and has become one of the world's major investment destinations. In 2012, the total production of Mexico's electronic industry reached a value of 67394.77 million USD, while exports totalled 78,117 million USD (Figure 2).

Within the last 30 years Baja California has become one of the most important electronics manufacturing regions in North America. Investment in the Electronic Components Market has reached up to $\$ 5$ billion and over 


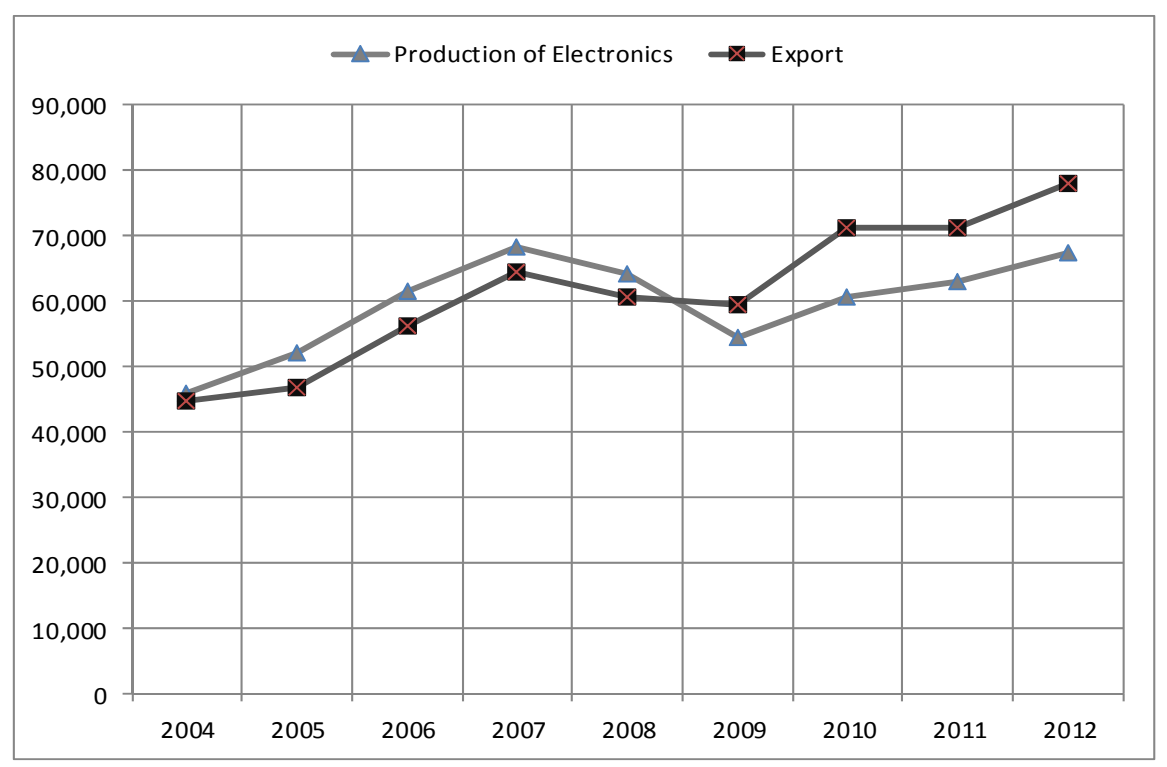

Figure 2. Production and export of electronics in Mexico.

Table 1. Electronic products exported by Mexico.

\begin{tabular}{ccc}
\hline Product & Million USD & Export Share \\
\hline Flat-screen television sets & 17,340 & $24.455 \%$ \\
Computer & 9,599 & $13.5 \%$ \\
Video Games consoles & 420 & $0.5 \%$ \\
Others & 34,732 & $48.4 \%$ \\
\hline
\end{tabular}

\$500 million has been invested in the Electronics Distribution Market. Baja California (B.C.) is well known for intellectual property protection, the safety of originnal products' rights. Every year more than 19 million high-tech televisions (LCD, DPL, Plasma) are manufactured in B.C. Other products manufactured include: circuit boards, audio/video components, computer devices, marine radars, cell phones, semiconductors and many more, companies in B.C. There are more than 200 companies in B.C.'s electronics sector, employing over 92,000 people.

\section{Methodology}

This paper addresses the problem of the domestic WEEE flow for which we have conducted a case study of one Mexican City. The city of Mexicali is located in the State of Baja California in the northern part of the country, on the border with the United States of America. In Mexicali, there are no mechanisms or management controls for the disposal of WEEE from domestic sources. The common form of management is in conjunction with MSW, which is disposed of in open dumps. However, a certain amount of WEEE is diverted from the flow through informal recycling such that an attempt to re- cover valuable components of the equipment could endanger public health and damage the environment due to incineration practices.

A search for viable alternatives for managing these wastes is required before considering a diagnosis of consumption practices and disposal of WEEE. Therefore, an investigation is performed in Mexicali to understand the perspectives of the waste generators.

For the determination and establishment of a waste management system, it is necessary to understand attitudes and disposition, as well as raise awareness to everyone involved throughout the life cycle of electronic products. In this study we examined the patterns of domestic use and disposal of WEEE. A survey was designed, which seeks to identify patterns of household WEEE and to determine the treatment of EEE in case of failure or breakdown. The survey was conducted in different areas of Mexicali, Baja California, with consideration of the various characteristics of their inhabitants. Areas were selected representing three socioeconomic strata (High, Medium and Low). To do this, the representative sample was determined considering a $90 \%$ confidence intervals. This work was conducted in three stages:

\subsection{Determination of the Representative Sample Population}

It was necessary to calculate the number of surveys to be applied according to the number of households by socioeconomic stratum. For this Equation (1), was applied by adjusting the degree of reliability mentioned above. The sample obtained $(n)$ by stratum is presented in Table 2 . 
Table 2. Representative sample size.

\begin{tabular}{ccc}
\hline Stratum & Households & $n$ \\
\hline High & $N=1262$ & 222 \\
Medium & $N=1520$ & 230 \\
Low & $N=1468$ & 229 \\
\hline
\end{tabular}

$$
n=\frac{N K^{2}}{N \beta^{2}+K^{2}}
$$

where:

$n=$ Sample size;

$N=$ Total number of households;

$K=$ Confidence level (95\%);

$\beta=$ Level of accuracy.

\subsection{Selection of Household}

Possible participants for conducting the survey were identified by considering the number of surveys required by stratum. A field survey was performed after identifying these sites. During the work, in the case of households did not have an adult for response, the survey was simple conducted at the next house.

\subsection{Assessment of Three Indicators of Consumption and Disposal Variability}

Finally, the variable consumption and disposal was assessed through three indicators:

Impact (CDI). This term refers to the amount of EEE in the categories of telecommunications, computer, entertainment and appliances present in the home. To determine the range and weighting of this variable, socioeconomic maximum and minimums for the available EEE were analyzed.

Consumption (CDC). This term identifies consumer practices at the time of acquisition. This was measured by if the acquired EEE are new or secondhand and if the EEE are highly efficient, namely, equipment with features that prevent damage to the environment.

Disposal (CDD). This term identifies disposal practices available for the EEE, either because they are no longer in use or are no longer functional.

The survey was applied to evaluate seven items in terms of their consumption and disposal. Table $\mathbf{3}$ shows the weight of the variable CDI, calculated from counting the household EEE in each stratum. Table 4 shows the range of the variable weighted Consumption and Disposal. Subsequently, the weighted data were exported to MatLab software for exploratory treatment and statistical analysis.

These data were normalized by dividing the larger value between registered. Were homogenized the scales each of concept weighted to simplify the analysis. Thus, each variable consists of values in the range of zero to one whereby NCDD = Standard Variable Disposal and NCDC $=$ Standard Variable Consumption.

\section{Results and Discussion}

Overall, 903 surveys were conducted in the three socioeconomic strata (232, 301 and 370 in the high, medium and low strata, respectively). As for impact caused by the consumption of EEE (CDI), the upper stratum displayed a 6.779, while the middle and lower stratum displayed 7.543 and 5.072, respectively. Notably, a house in the upper stratum has an average of 29 EEE, a household in the middle stratum has 25 and one in the lower stratum has 13. The EEE category with the highest percentage in households is appliances, while computers contribute to a lesser extent. Table 5 shows the percentages of each category of EEE recorded at the households and the maximum number of EEE $(\mathrm{M})$ recorded in a home (CDI).

In Figure 3, shows the disposal percentage of six EEE in households by socioeconomic status.

Table 6 shows the percentages of households at each level of consumption (CDC). It is observed that for the low stratum, the consumption level is medium-low (85.7\%).

Table 3. Impact on consumption of EEE.

\begin{tabular}{cccc}
\hline \multirow{2}{*}{ Category } & \multicolumn{3}{c}{ Stratum } \\
\cline { 2 - 4 } & High & Medium & Low \\
\hline Telecommunications & $0-21$ & $0-22$ & $0-20$ \\
Office \& Information & $0-25$ & $0-25$ & $0-6$ \\
Entertainment & $0-34$ & $0-30$ & $0-23$ \\
Small Household Appliances & $0-38$ & $0-10$ & $0-24$ \\
\hline
\end{tabular}

Table 4. Weighting the variables consumption and disposal.

\begin{tabular}{cc}
\hline \multicolumn{2}{l}{ Weighted Values Range in the Survey } \\
\hline Disposal & $0-23$ \\
Consumption & $0-8$ \\
\hline
\end{tabular}

Table 5. Electrical and electronic equipments in the households.

\begin{tabular}{lccccccc}
\hline \multirow{1}{*}{ Category } & \multicolumn{7}{c}{ Stratum } \\
\cline { 2 - 7 } & High \% & M & Medium \% & M & Low \% & M \\
\hline Telecommunications & 23.4 & 21 & 20.1 & 22 & 16.2 & 20 \\
Office \& Information & 11.3 & 25 & 11.9 & 25 & 5.0 & 6 \\
Entertainment & 25.6 & 34 & 26.0 & 30 & 26.0 & 23 \\
Small Household & 39.8 & 38 & 42.0 & 10 & 52.8 & 24 \\
Appliances & & & & & & & \\
\hline
\end{tabular}




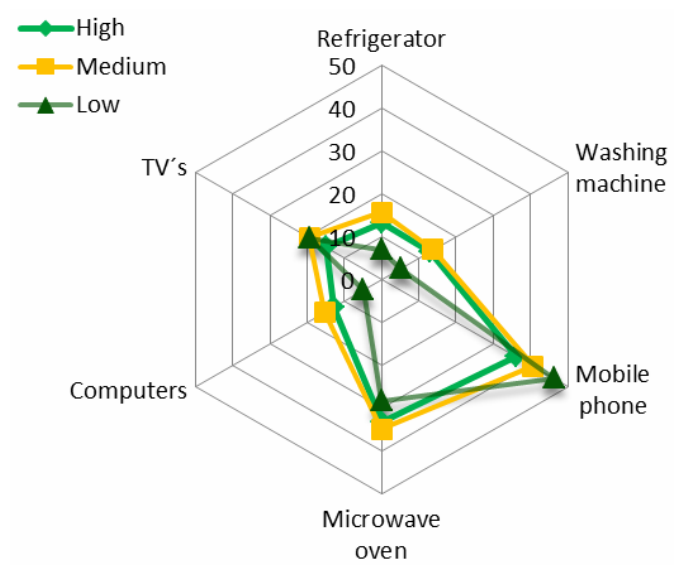

Figure 3. Management practices for six EEE (disposal).

Table 6. Level of consumption of EEE.

\begin{tabular}{lllll}
\hline \multirow{2}{*}{$\begin{array}{l}\text { Consumption } \\
\text { Level }\end{array}$} & Scale & \multicolumn{3}{c}{ Stratum } \\
\cline { 3 - 5 } & & High \% & Medium \% & Low \% \\
\hline Low & $0-2$ & 3.5 & 14 & 46.2 \\
Medium & $3-5$ & 10.4 & 33 & 39.6 \\
High & $6-8$ & 86.1 & 52.2 & 14.3 \\
\hline
\end{tabular}

For the middle stratum, the consumption level is medium-high (85.2\%), and the consumption level for the high stratum is high (86\%). As the stratum level increases, the consumption practices are more environmentally positive.

Table 7, shows the layout for the variable percentages (CDD), established on the three levels. Note that the highest level $(\mathrm{H})$ describes the households that take steps to cause the least environmental impact at the time of disposal of the WEEE.

At the moment in Mexico, the adequate management of the electronic waste is unsatisfactory, although there is an environmental normativity frame, the instrumentation elements have not been efficient, therefore the generators of these electronic residuals ignore or do not fulfill them and neither allocate resources for their proper management.

For these reasons is necessary that the federal, state and municipal environmental authorities in coordination with the generators, producers, and the society in general design and implement an efficient environmental management of the electronic residuals. It is important to emphasize that of any kind of waste flow the waste characterization it is the first step to plan adequately their integral management. In the same for waste of the electric and electronic equipment (WEEE), therefore the knowledge of the composition and the quantity of the generation allows to plan strategies in the life cycle of the product, as much as alternatives for its recovery. In
Table 7. Disposal level.

\begin{tabular}{ccccc}
\hline \multirow{2}{*}{$\begin{array}{l}\text { Disposal } \\
\text { Level }\end{array}$} & Scale & \multicolumn{3}{c}{ Stratum } \\
\cline { 3 - 5 } & & High \% & Medium \% & Low \% \\
\hline Low & $0-7$ & 27.6 & 20 & 25.7 \\
Medium & $8-15$ & 42.6 & 47.4 & 44.4 \\
High & $16-23$ & 29.7 & 32.6 & 30 \\
\hline
\end{tabular}

view of the constant generation of this waste it is of great importance to understand their behavior, forms of treatment, elimination, disposition, with the objective of minimizing the damage to the ecosystem and public health.

The best environmental option for the management of the WEEE is always when possible the separation or reutilization of the accessories or equipments thus avoiding to become residuals. For that it is required a logistic that allows to maintain the characteristics of the equipment with the right type of recollection, transportation, classification and storage to avoid the damage or impairment that would halt its reutilization.

Another option for its management is to dismount or to triturate them for recycling. The recycling of the WEEE requires a previous treatment and, if possible, the substitution of the hazard materials and substances for other less pollutant, since when the dismantling procedure is not carried out rightly, the hazard substances that are contained in the electric and electronic equipment (EEE) may contaminate the recovered materials

It is important to implement strategies to start a management of WEEE in the region whereby the most important actors get involved, such as producers, importers, traders, distributors, government and consumers, amongst them. By the same token, it is important to promote practices of reutilization to extend the useful life of the second hand electric and electronic equipment to reintroduce them in the market, before they are recycled.

To get an integral management of electric-electronic waste is necessary to consider the application of hierarchical measures which may start at the prevention of the generation, the separation from the source, the reutilization and the recycling up to the adequate final disposition as the last option. In parallel is required to make a recount or incorporate actively to the chain of actors involved the life cycle of the products until it becomes a residual, in the solution of the problems associated to the generation and adequate management of the residuals, within the limits of the responsibility of each actor.

Every day is produced tons of solid residuals, including the WEEE, and this figure does not stop counting, the storage of this material is not a sustainable solution and their destruction does not result satisfactory due to their 
composition. The best solution consist in preventing the generation of residual and reintroducing them in the production cycle by using diverse forms of recuperation and valorization such as recycling of components when there exist sustainable solutions from the ecological, technological, economical and social view point.

\section{Conclusions}

Through this research, we observed that, in the case of the higher stratum, which has a higher level of consumption, it is not possible to conclude that there is a conscious consumer decision that is environmentally friendly. The results only indicate a possible relationship between consumption and purchasing power of the population. So in future, the research is suggested to add re- agents and variables related to environmental knowledge of the home generator, habits and practices in the use and management of EEE to provide more information and to help identify patterns of behavior of the variables analyzed.

It is noted that consumer electronics and small EEE as the cellular and microwave are that more WEEE disposed within the flow of MSW. Large household appliances such as refrigerators, washing machines, televisions and even laptops are computers that most are intended for storage, sale or repair.

In search of alternatives for managing these wastes, is it necessary for all sectors and actors involved in the life cycle of WEEE from their generation, so this study aimed at analyzing the landscape of practices generation, consumption and WEEE disposal in seeking to establish background and possible strategies that support the need to implement efficient measures and recovery of waste.

Five broad parameters were identified by Widmer [2] as essential in designing an effective WEEE management system. These include: legal regulation, system coverage, system financing, producer responsibility, and ensuring effective compliance. Referring to the layout and easy access in our city to the acquisition of EEE secondhand, it is necessary to ensure an effective system of control and restrictions on the importation of EEE, such as: certification of functionality and lifetime.

\section{REFERENCES}

[1] D. Sinha-Khetriwal, P. Kraeuchi and M. Schwaninger, “A Comparison of Electronic Waste Recycling in Switzerland and in India," Environmental Impact Assessment Re- view, Vol. 25, No. 5, 2005, pp. 492-504.

[2] R. Widmer, H. Oswald-Krapf, D. Sinha-Khetriwal, M. Schnellmann and H. Böni, "Global Perspectives on EWaste," Environmental Impact Assessment Review, Vol. 25, No. 5, 2005, pp. 436-458. doi:10.1016/j.eiar.2005.04.001

[3] S. Schwarzer, A. De Ono, P. Peduzzi, G. Giuliani and S. Kluser, "E-Waste, the Hidden Side of IT Equipment's Manufacturing and Use," 2005. http://ewasteguide.info/biblio/e-waste-the-h

[4] "Electronic Components Industry Profile: Global 2012," Business Source Complete, 2013, pp. 1-34.

[5] Proméxico, "Investment and Trade. Industry Profiles. Sector Profile: Electric-Electronic in Mexico,” 2011. http://mim.promexico.gob.mx

[6] Z. Wei-Hua, W. Ying-Xin and M. O. Simonnot, "Soil Contamination Due to E-Waste Disposal and Recycling Activities: A Review with Special Focus on China," $P e$ dosphere, Vol. 22, No. 4, 2012, pp. 434-455. doi:10.1016/S1002-0160(12)60030-7

[7] D. S. Khetriwal, P. Kraeuchi and R. Widmer, "Producer Responsibility for E-Waste Management: Key Issues for Consideration-Learning from the Swiss Experience, Journal of Environment Management, Vol. 90, No. 1, 2009, pp. 153-165. doi:10.1016/j.jenvman.2007.08.019

[8] A. Bandyopadhyay, "Indian Initiatives on E-Waste Management-A Critical Review,” Environmental Engineering Science, Vol. 25, No. 10. 2008, pp. 1507-1526. doi:10.1089/ees.2007.0342

[9] R. J. Slack, J. R. Gronow and N. Voulvoulis, "Hazardous Components of Household Waste, Critical Reviews," Environmental Science and Technology, Vol. 34, No. 5, 2004 pp. 419-445 doi:10.1080/10643380490443272

[10] Secretary of Environmental and Natural Resources (SEMARNAT), "National Programme for the Prevention and Management of Waste 2009-2012,” http://relascmex.files.wordpress.com/2009/11/programan alresiduos2009-2012-oct2009.pdf

[11] K. Huang, J. Guo and X. Zhenming, "Recycling of Waste Printed Circuit Boards: A Review of Current Technologies and Treatment Status in China,” Journal of Hazardous Materials, Vol. 164, No. 2-3, 2009, pp. 399-408. doi:10.1016/j.jhazmat.2008.08.051

[12] Promexico, "Investment and Trade. Appliances Report," 2012. http://mim.promexico.gob.mx

[13] Promexico, “Business Intelligence Unit,” 2012. http://mim.promexico.gob.mx/wb/mim/inicio 